clipped only the extremity of the tarsus for a length of I of an inch. Nevertheless, the shell did not drop off, on the beetle when caught shaking its leg violently. The specimen was brought home in a handkerchief, and placed after about three hours in water; and the shell remained attached from February 18 to 23 , when it dropped off, being still alive, and so remained for about a fortnight while in my possession. Shortly after the shell had detached itself, the beetle dived to the bottom of the vessel in which it had been placed, and having inserted its antennæ between the valves, was again caught for a few minutes. The species of Dytiscus of ten fly at night, and no doubt they generally alight on any pool of water which they may see; and I have several times heard of their having dashed down on glass cucumber frames, no doubt mistaking the glittering surface for water. I do not suppose that the above weight of 6 grains would prevent so powerful an insect as a Dytiscus from taking flight. Anyhow this beetle could transport smaller individuals; and a single one would stock any isolated pond, as the species is an hermaphrodite form. $\mathrm{Mr}$. Crick tells me that a shell of the same kind, and of about the same size, which he kept in water "extruded two young ones, which seemed very active and able to take care of themselves." How far a Dytiscus could fly is not known; but during the voyage of the Beagle a closelyallied form, namely, a Colymbetes, flew on board when the nearest point of land was forty-five miles distant; and it is an improbable chance that it had flown from the nearest point.

$\mathrm{Mr}$. Crick visited the same pond a fortnight afterwards, and found on the bank a frog which appeared to have been lately killed; and to the outer toe of one of its hind legs a living shell of the same species was attached. The shell was rather smaller than in the previous case. The leg was cut off and kept in water for two days, during which time the shell remained attached. The leg was then left in the air, but soon became shrivelled; and now the shell being still alive detached itself.

Mr. F. Norgate, of Sparham, near Norwich, in a letter dated March 8, I88I, informs me that the larger waterbeetles and newts in his aquarium "frequently have one foot caught by a small freshwater bivalve (Cyclas cornea?), and this makes them swim about in a very restless state, day and night, for several days, until the foot or toe is completely severed." $\mathrm{He}$ adds that newts migrate at night from pond to pond, and can cross over obstacles which would be thought to be considerable. Lastly, my son Francis, while fishing in the sea off the shores of North Wales, noticed that mussels were several times brought up by the point of the hook ; and though he did not particularly attend to the subject, he and his companion thought that the shells had not been mechanically torn from the bottom, but that they had seized the point of the hook. A friend also of Mr. Crick's tells him that while fishing in rapid streams he has often thus caught small Unios. From the several cases now given, there can, I think, be no doubt that living bivalve shells must often be carried from pond to pond, and by the aid of birds occasionally even to great distances. I have also suggested in the "Origin of Species" means by which freshwater univalve shells might be far transported. We may therefore demur to the belief doubtfully expressed by Mr. Gwyn Jeffreys in his "British Conchology," namely, that the diffusion of freshwater shells "had a different and very remote origin, and that it took place before the present distribution of land and water.'

\section{CHARLES DARWIN}

\section{THE FISHER Y EXHIBITION AT EDINBURGH}

$\mathrm{T}$ has now been placed beyond doubt that this exhibition will prove successful, so far as a great show of interesting exhibits is concerned. Such exhibitions, of course, partake in some degree of the nature of a commercial adventure - the projectors being dependent on the gate money to pay the expenses incurred, which are naturally heavy-although the prize list has been largely contributed to by private individuals and public bodies. Such an exhibition being a novelty will no doubt attract, from day to day, a considerable body of spectators, although it is deprived of many attractive features by reason of the place of exhibition not being fixed on the immediate sea-coast. It would have proved interesting, could the spectators have been shown the beam trawl at work, or have had displayed before them a suite of herring nets, or other items of the machinery of fish capture. Such apparatus will be largely displayed in the place of exhibition, but their effects cannot so well be judged as when they are seen in action. Upwards of seventy prizes are offered for "exhibits" and "essays"; the latter, indeed, seem to be a chief feature of the exhibition, and if they can be utilised for behoof of the public and the fisher people, some good may result. But, although a large number of prizes were given for essays at the Norwich Fishery Exhibition of last year, the public have not been made any the wiser in consequence. A very handsome surplus resulted from the Norwich exhibition-nearly a thousand pounds it is said. Why, then, has not a portion of that sum been devoted to the dissemination of the knowledge contained in the prize essays? As regards the " exhibits," they can always be seen and understood by those who please to look at them, and if there are half a dozen of the same sort, they can be compared one with the other, and the decisions of the judges can be criticised, so that persons in search of new boats or other fishing gear, can give their orders for the same in the direction they think most suitable. But with respect to the essays the knowledge contained in these productions-judging from what took place at Norwich-will remain buried in the brains of the committee! Of what possible use is it to bestow a prize on the writer of an essay, "On the Fish Supplies of Great Cities, with special reference to the best Methods of Catching and Packing," if the knowledge thus obtained is never to become public? The prize list of the Edinburgh Exhibition is rich in material for the essayist, many subjects of interest in the fishery world being selected for illustration, such as the salmon disease, oyster culture, the migrations and spawning of sea fish, the utilisation of fish offal, the best methods of preserving fish alive for markets, the pollution of rivers, the natural history of the herring, and twenty other subjects. In view of the still larger international fishery exhibition, which will take place in London next year, it is time this ques. tion of "what ought to be done with the prize essays," should be ventilated and settled. Up till this moment it remains a blot on the Norwich exhibition that none of the prize essays sent there have been made public. So far as we know, only one of the essays has become accessible ; that is the essay, on the salmon disease, by Sir James Gibson Maitland, which, however, was printed at the baronet's own expense. The exhibition at Edinburgh will be very much on the lines of those which took place some years ago at the Hague and Arcachon, except that the most attractive feature of the latter exhibition will be wanting in the well-arranged aquarium. Neither in Edinburgh nor in London can we hope to compete with the great fishery show of Berlin, which was undoubtedly very complete, the American national exhibits being of much interest. At home we have no fishery collection of a national kind, if we except Buckland's Museum of Economic Fish Culture; and, so far, we are at a disadvantage with the United States, which possesses a very complete collection of fishery apparatus of all kinds. It is to be hoped, in the circumstances, that America will do for this country what it did for Germany, give us an opportunity of seeing and judging for ourselves how far 
they are ahead of us in fishery economy. We -shall doubtless be able, when the exhibition opens, to find some points of interest worthy of being alluded to in a future number of NATURE.

\section{THE WINGS OF PTERODACTYLES}

THE first Pterosaurians discovered were recognised as flying animals, but were thought to be bats. As soon as their general structure became known, they were classed with the reptiles, although it was considered possible that their power of flight was due to feathers. Later their bones were mistaken for those of birds by various experienced anatomists, and others regarded them as sharing important characters with that group. Some anatomists, however, believed that the fore-limbs of Pterodactyles were used for swimming rather than for flight, and this view has found supporters within the present decade. A single fortunate discovery, made a few years since, has done much to settle the question as to the wings of Pterodactyles, as well as their mode of flight, and it is the aim of the present article to place on record some of the more important facts thus brought to ight.
The specimen to be described was found in 1873 , near Eichstädt, Bavaria, in the same lithographic slates that have yielded Archoopteryx, Compsognathus, and so many other Jurassic fossils known to fame. This specimen, which represents a new species of the genus Rhamphorhynchus, is in a remarkable state of preservation. The bones of the skeleton are nearly all in position, and those of both wings show very perfect impressions of volant membranes still attached to them. Moreover, the extremity of the long tail supported a separate vertical membrane, which was evidently used as a rudder in flight. These peculiar features are well shown ln Fig. I, which represents the fossil one-fourth the natural size.

The discovery of this unique specimen naturally attracted much attention at the time, and many efforts were made to secure it for European museums. The writer was then at work on the toothless Pterodactyles which he had recently found in the Cretaceous of Kansas, and believing the present specimen important for his investigations, sent a message by cable to a friend in Germany, and purchased it for the museum of Yale College, where it is now deposited.

The Wing Membranes.-A careful examination of this fossil shows that the patagium of the wings was a thin

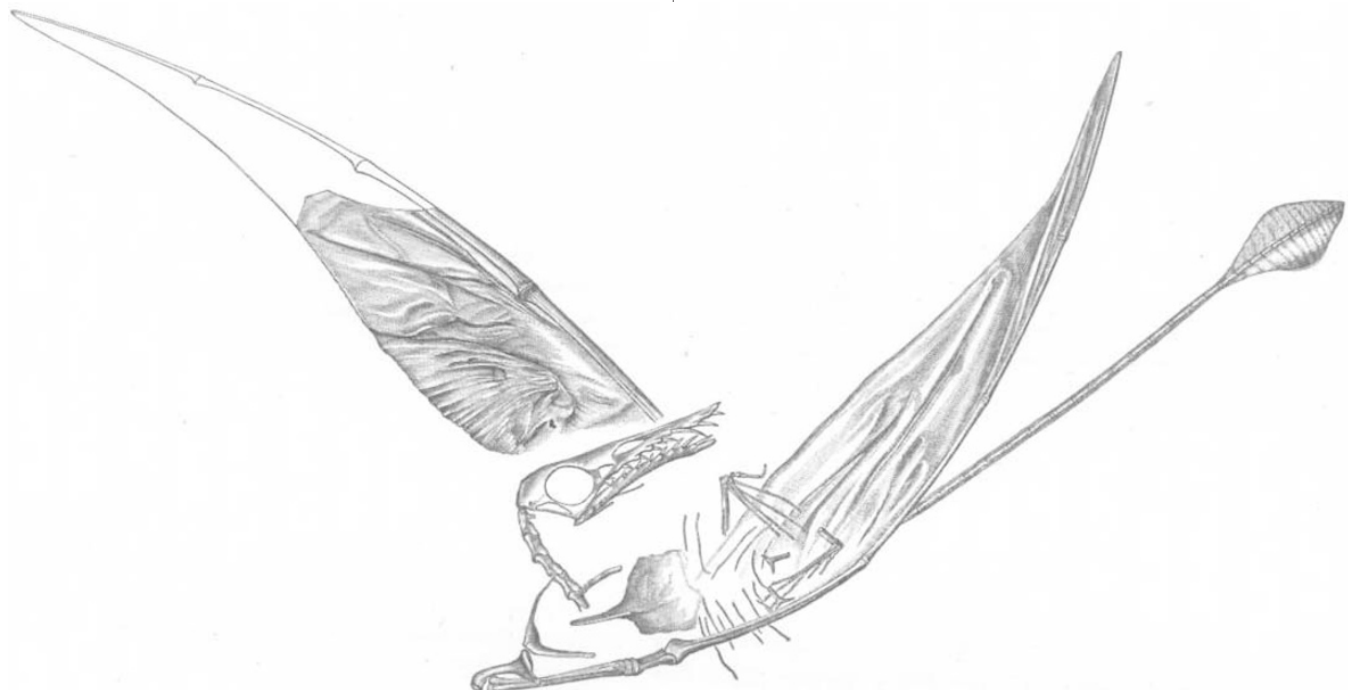

FIG. 1.-Rhomphorhynchus phyllurus, Marsh. One-fourth natural size. The animal lies uron the lack, and the under surfaces of the wing membranes are exposed. The caudal membrane is seen from the left side.

smooth membrane, very similar to that of modern bats. As the wings were partially folded at the time of entombment, the volant membranes were naturally contracted into folds, and the surface was also marked by delicate striæ. At first sight, these striæ might readily be mistaken for a thin coating of hair, but on closer investigation they are seen to be minute wrinkles in the surface of the membranes, the under-side of which is exposed. The wing membranes appear to have been attached in front along the entire length of the arm, and out to the end of the elongated wing finger. From this point the outer margin curved inward and backward, to the hind foot.

The membrane evidently extended from the hind foot to near the base of the tail, but the exact outline of this portion cannot at present be determined. It was probably not far from the position assigned it in the restoration attempted in the cut given below, Fig. 3. The attachment of the inner margin of the membrane to the body was doubtless similar to that seen in bats and flying squirrels.

In front of the arm there was likewise a fold of the

I Cormunicated by the a uthor. This article will also appear in the American Fournal of Science for April. skin extending probably from near the skoulder to the wrist, as indicated in Fig. 3. This fold inclosed a peculiar bone (pteroid), the nature and function of which will be discussed below in considering the osteology of this part of the skeleton.

The Caudal Membrane.-The greater portion of the tail of this specimen was free, and without volant attachments. The distal extremity, however, including the last sixteen short vertebræ, sufported a vertical membrane, which is shown in Fig. I and also in Fig. 2. This feculiar caudal appendage was of somewhat greater thickness than the patagial membrane of the wings. It was rbomboid in outline, and its upper and lower portions were slightly unequal in form and size. The upper part was kept in position by a series of spines, sent off one from near the middle of each vertebral centrum, and thus clearly representing neural spines. The lower half also was strengthened by similar spines, which descended from near the junction of the vertebra, and hence were homologous with chevron bones. These spines were cartilaginous, and flexible, but sufficiently firm in texture to keep the membrane in an upright position.

The Scapular Arch.-The osteology of the scapular 